\title{
A preparation of murine liver fragments for in vitro studies: liver preparation for toxicological studies
}

\author{
Ali S Alfazari', Bayan Al-Dabbagh', Saeeda Almarzooqi ${ }^{2}$, Alia Albawardi ${ }^{2}$ and Abdul-Kader Souid ${ }^{3 *}$
}

\begin{abstract}
Background: The aim of this study was to develop liver tissue preparation suitable for investigating toxins. Hepatocyte respiration, ATP content, urea synthesis, caspase activity and morphology were measured as a function of in vitro incubation time. Mice were anesthetized by sevoflurane inhalation. Small liver fragments were then rapidly excised and incubated at $37^{\circ} \mathrm{C}$ in Krebs-Henseleit buffer (continuously gassed with $95 \% \mathrm{O}_{2}: 5 \% \mathrm{CO}_{2}$ ) for up to $6 \mathrm{~h}$. Phosphorescence $\mathrm{O}_{2}$ analyzer was used to determine the rate of cellular mitochondrial $\mathrm{O}_{2}$ consumption $\left(k_{c}, \mu \mathrm{M}\right.$ $\mathrm{O}_{2} \mathrm{~min}^{-1} \mathrm{mg}^{-1}$ ). Cellular ATP was measured using the luciferin/luciferase system. The caspase-3 substrate $\mathrm{N}$-acetylasp-glu-val-asp-7-amino-4-methylcoumarin (Ac-DEVD-AMC) was used to monitor intracellular caspase activity; cleaved AMC moieties (reflecting caspase activity) were separated on HPLC and detected by fluorescence.

Findings: Respiration was inhibited by cyanide, confirming the oxidation occurred in the respiratory chain. The values of $k_{c}$ (mean $\pm \mathrm{SD}$ ) for $0 \leq t \leq 6 \mathrm{~h}$ were $0.15 \pm 0.02 \mu \mathrm{M} \mathrm{O}_{2} \mathrm{~min}^{-1} \mathrm{mg}^{-1}(\mathrm{n}=18$, coefficient of variation, $\mathrm{CV}=13 \%)$, ATP content $131 \pm 69 \mathrm{pmol} \mathrm{mg}^{-1}(1 \leq t \leq 6 \mathrm{~h}, \mathrm{n}=16, \mathrm{CV}=53 \%)$, synthesized urea $0.134 \pm 0.017 \mathrm{mg} / \mathrm{dL} \mathrm{mg}^{-1}$ in $50 \mathrm{~min}$ $(0 \leq t \leq 6 \mathrm{~h}, \mathrm{n}=14, \mathrm{CV}=13 \%)$, and AMC peak area $62,540 \pm 26,227$ arbitrary units $\mathrm{mg}^{-1}(1 \leq t \leq 6 \mathrm{~h}, \mathrm{n}=3, \mathrm{CV}=42 \%)$. Hepatocyte morphology and organelles were reasonably persevered.
\end{abstract}

Conclusions: The described liver tissue preparation demonstrates stable hepatocyte structure, ultrastructure and biomarkers for up to $6 \mathrm{~h}$, permitting in vitro studies.

Keywords: In vitro, Cytotoxicity, Apoptosis, Liver, Mice, Cellular respiration, Bioenergetics, Caspases

\section{Findings}

Utilization of murine liver tissue for in vitro toxicological studies is recently reported [1-3]. In these studies, the measurements were limited to cellular mitochondrial $\mathrm{O}_{2}$ consumption (cellular respiration) and morphology. A more comprehensive assessment of hepatocyte functions, however, is frequently required. The present study includes additional hepatocyte biomarkers (ATP content, urea synthesis and caspase activity) in a preparation that is stable in vitro for up to $6 \mathrm{~h}$.

The term cellular bioenergetics refers to the biochemical processes involved in energy metabolism (energy conversion or transformation). Cellular respiration, on the other hand, implies the delivery of $\mathrm{O}_{2}$ and metabolic

\footnotetext{
* Correspondence: asouid@uaeu.ac.ae

${ }^{3}$ Departments of Pediatrics, United Arab Emirates University, P.O. Box 15551, Al Ain, UAE

Full list of author information is available at the end of the article
}

fuels to the mitochondria, the oxidation of reduced metabolic fuels with passage of electrons to $\mathrm{O}_{2}$, and the synthesis of ATP. Impaired bioenergetics or respiration, thus, entails an interference with any of these processes.

Impairments in the cellular membranes, mitochondria or metabolic enzymes are expected to disrupt energy production within the cells. Cellular bioenergetics, thus, can be used as a biomarker of drug-induced cytotoxicities [4].

The term apoptosis describes cellular mechanisms responsible for initiating and executing cell death. The "initiation" process requires leakage of cytochrome c and other pro-apoptotic molecules from the mitochondrial intermembrane space into the cytosol. In the cytosol, cytochrome $\mathrm{c}$ binds to the apoptotic protease activating factor-1 (Apaf-1), triggering the cascade of caspases (a series of cysteine, aspartate-specific proteases) [5]. Caspase activation executes mitochondrial dysfunction, cellular membrane disruption (e.g., phosphatidylserine 
exposure) and DNA fragmentation. The mitochondrial perturbation involves opening the permeability transition pores (accelerating oxidations in mitochondrial respiratory chain) and collapsing the electrochemical potential [6]. Cytochrome c- and apoptosome-independent pathways for caspase activation are also known [7]. Thus, initiation and execution of apoptosis are directly linked to mitochondria. The fate of the cell is determined by the severity of cellular derangements and the capacity of cellular repair mechanisms. Cellular bioenergetics (ATP turnover) plays vital roles in repairing the caspase-induced damages [8]. Thus, the appearance of intracellular biomarkers for apoptosis does not necessarily indicate cell death.

Cells with intact bioenergetics are more capable of repairing toxic damages. Cellular ATP depletion, on the other hand, inevitably leads to cell death. Thus, apoptosis (intracellular caspase activity) is more likely to result in cell death if the cellular bioenergetics is impaired. This fact stems from the cellular dependency on aerobic metabolism. In contrast, cancer cells are more capable of surviving on anaerobic metabolism (a process termed "aerobic glycolysis" or Warburg effect) [9].

The study here assessed liver tissue bioenergetics (respiration and ATP content), urea synthesis, intracellular caspases, structure and ultrastructure in a preparation that is reasonably stable in vitro for up to $6 \mathrm{~h}$. The measured biomarkers are suitable for in vitro investigation of effects of pathogens and toxins on the liver.

\section{Materials and methods}

$\operatorname{Pd}(\mathrm{II})$ complex of meso-tetra-(4-sulfonatophenyl)tetrabenzoporphyrin (Pd phosphor) was purchased from Porphyrin Products (Logan, UT). A lyophilized powder of caspase inhibitor I [ $N$-benzyloxycarbonyl-val-ala-asp $(\mathrm{O}-$ methyl)-fluoromethylketone; zVAD-fmk; $m . w .=467.5$; pan-caspase inhibitor] was purchased from Calbiochem (La Jolla, CA). Ac-DEVD-AMC ( $N$-acetyl-asp-glu-val-asp7-amino-4-methylcoumarin; $m . w .=675.64$; caspase-3 substrate) was purchased from Axxora LLC (San Diego, CA). Glucose (anhydrous) and remaining reagents were purchased from Sigma-Aldrich (St. Louis, MO).

zVAD-fmk solution $(2.14 \mathrm{mM})$ was made by dissolving $1.0 \mathrm{mg}$ in $1.0 \mathrm{~mL}$ dimethyl sulfoxide and stored at $-20^{\circ} \mathrm{C}$ in small aliquots. Ac-DEVD-AMC solution $(7.4 \mathrm{mM})$ was made by dissolving $5.0 \mathrm{mg}$ in $1.0 \mathrm{~mL}$ dimethyl sulfoxide and stored at $-20^{\circ} \mathrm{C}$. Pd phosphor solution $(2.5 \mathrm{mg} / \mathrm{ml}=2 \mathrm{mM})$ was prepared in $\mathrm{dH}_{2} \mathrm{O}$ and stored at $-20^{\circ} \mathrm{C}$ in small aliquots. Sodium cyanide $(\mathrm{NaCN})$ solution $(1.0 \mathrm{M})$ was prepared in $\mathrm{dH}_{2} \mathrm{O}$; the $p \mathrm{H}$ was adjusted to $\sim 7.0$ with $12 \mathrm{~N} \mathrm{HCl}$ and stored at $-20^{\circ} \mathrm{C}$. Glucose oxidase $(10 \mathrm{mg} / \mathrm{mL})$ was dissolved in $\mathrm{dH}_{2} \mathrm{O}$ and stored at $20^{\circ} \mathrm{C}$. Krebs-Henseleit (KH) buffer $(115 \mathrm{mM} \mathrm{NaCl}$, $25 \mathrm{mM} \mathrm{NaHCO}, 1.23 \mathrm{mM} \mathrm{NaH}{ }_{2} \mathrm{PO}_{4}, 1.2 \mathrm{mM} \mathrm{Na}_{2} \mathrm{SO}_{4}$,
$5.9 \mathrm{mM} \mathrm{KCL}, 1.25 \mathrm{mM} \mathrm{CaCl}_{2}, 1.18 \mathrm{mM} \mathrm{MgCl}_{2}$ and $10 \mathrm{mM}$ glucose, $p \mathrm{H} \sim 7.4$ ) was made fresh.

\section{Animals}

Male mice (Taylor outbred and C57Bl/6 strains, 8-10 weeks old, weighing about 25-30 grams) were used in this study. The animals were maintained at the animal facility that was in compliance with the National Institutes of Health guidelines (http://grants.nih.gov/ grants/olaw/references/phspol.htm). All animals were housed in rooms maintained at $22^{\circ} \mathrm{C}$ with $\sim 60 \%$ relative humidity and a 12-h light/dark cycle. They had ad libitum access to standard rodent chow and filtered water.

\section{Ethic statement}

The study was approved by the Animal Ethics Committee United Arab Emirates University - College of Medicine and Health Sciences. The study was carried out in strict accordance with the recommendations in the Guide for the Care and Use of Laboratory Animals of the National Institutes of Health. All surgery was performed under anesthesia, and all efforts were made to minimize suffering.

\section{Liver tissue}

The animals were anesthetized by sevoflurane inhalation $(100 \mu \mathrm{L}$ per $10 \mathrm{~g})$ and sacrificed as outlined [1,2]. Liver specimens ( 20 to $30 \mathrm{mg}$ ) were collected using a 4-mm human skin biopsy punch (Miltex $\mathrm{GmbH}$, Germany). Collected fragments were immediately immersed in continuously gassed with $95 \% \mathrm{O}_{2}: 5 \% \mathrm{CO}_{2}$ ice-cold $\mathrm{KH}$ buffer. For $\mathrm{O}_{2}$ measurements, specimens were placed in $1.0 \mathrm{~mL} \mathrm{KH}$ buffer containing $0.5 \%$ fat-free bovine albumin and $3 \mu \mathrm{M} \mathrm{Pd}$ phosphor. Specimens were also processed for measuring caspase activity and ATP content as described below.

\section{Intracellular caspase activity}

Liver specimens were collected from mice as described [1]. The samples were incubated in vitro at $37^{\circ} \mathrm{C}$ in $50 \mathrm{~mL} \mathrm{KH}$ buffer (continuously gassed with $95 \% \mathrm{O}_{2}: 5 \% \mathrm{CO}_{2}$ ) for up to $6 \mathrm{~h}$. At specific time points, samples were incubated in oxygenated $\mathrm{KH}$ buffer with $32 \mu \mathrm{M}$ zVAD-fmk or $15 \mu \mathrm{L}$ DMSO for $20 \mathrm{~min}(\mathrm{f} / \mathrm{v}=1.0 \mathrm{~mL})$. Ac-DEVD-AMC $(37 \mu \mathrm{M})$ was then added and the incubation continued for additional $20 \mathrm{~min}$. At the end of incubation, the tissue was disrupted by vigorous homogenization for $2 \mathrm{~min}$, sonication for $3 \mathrm{~min}$ and 10 passages through a 27-G needle. The tissue disruption procedure quenched the Ac-DEVD-AMC cleavage reaction, mainly since caspases became practically inactive due to dilution. The supernatant was collected by centrifugation ( 16,300 $\mathrm{g}$ for $90 \mathrm{~min}$ ) through Microcentrifuge Filter (nominal molecular weight limit $=10,000$ Dalton, Sigma ${ }^{\circ}$, separated on HPLC, and analyzed for the free fluorogenic AMC moiety. 


\section{HPLC}

The analysis was performed on a Waters reversed-phase HPLC system, which consisted of a manual injector, a pump and a fluorescent detector. The column, $4.6 \times$ $250 \mathrm{~mm}$ Beckman Ultrasphere IP column, was operated at $25^{\circ} \mathrm{C}$ at $1.0 \mathrm{ml} / \mathrm{min}$. For $\mathrm{AMC}$ detection, the excitation wavelength was $380 \mathrm{~nm}$ and the emission wavelength $460 \mathrm{~nm}$. Solvents A and B were HPLC-grade methanol: $\mathrm{dH}_{2} \mathrm{O}$ 1:1 (isocratic). The run time was $20 \mathrm{~min}$ and the injection volume was $20 \mu \mathrm{L}$.

\section{Oxygen measurement}

A phosphorescence $\mathrm{O}_{2}$ analyzer was used to monitor $\mathrm{O}_{2}$ consumption by liver specimens $[1,2]$. Briefly, $\mathrm{O}_{2}$ detection was performed with the aid of Pd phosphor (absorption maximum at $625 \mathrm{~nm}$ and phosphorescence maximum at $800 \mathrm{~nm})$. Samples were exposed to light flashes (600 per min) from a pulsed light-emitting diode array with peak output at $625 \mathrm{~nm}$ (OTL630A-5-10-66-E, Opto Technology, Inc., Wheeling, IL). Emitted phosphorescent light was detected by a Hamamatsu photomultiplier tube after passing through an interference filter centered at $800 \mathrm{~nm}$. The amplified phosphorescence decay was digitized at $1.0 \mathrm{MHz}$ by a 20-MHz A/D converter (Computer Boards, Inc., Mansfield, MA).

A program was developed using Microsoft Visual Basic 6, Microsoft Access Database 2007, and Universal Library components (Universal Library for Measurements Computing Devices; http://www.mccdaq.com/daq-software/ universal-library.aspx). It allowed direct reading from the PCI-DAS 4020/12 I/O Board (PCI-DAS 4020/12 I/O Board; http://www.mccdaq.com/pci-data-acquisition/PCIDAS4020-12.aspx). The pulse detection was accomplished by searching for 10 phosphorescence intensities $>1.0$ volt (by default). Peak detection was accomplished by searching for the highest 10 data points of a pulse and choosing the data point closest to the pulse decay curve [10].

The phosphorescence decay rate $(1 / \tau)$ was characterized by a single exponential; $\mathrm{I}=\mathrm{Ae}^{-t / \tau}$, where $\mathrm{I}=\mathrm{Pd}$ phosphor phosphorescence intensity. The values of $1 / \tau$ were linear with dissolved $\mathrm{O}_{2}: 1 / \tau=1 / \tau^{\mathrm{o}}+k_{q}\left[\mathrm{O}_{2}\right]$, where $1 / \tau=$ the phosphorescence decay rate in the presence of $\mathrm{O}_{2}, 1 / \tau^{\mathrm{O}}=$ the phosphorescence decay rate in the absence of $\mathrm{O}_{2}$, and $k_{\mathrm{q}}=$ the second-order $\mathrm{O}_{2}$ quenching rate constant in $\mathrm{s}^{-1} \cdot \mu \mathrm{M}^{-1}[11]$.

Liver tissue respiration was measured at $37^{\circ} \mathrm{C}$ in $1-\mathrm{mL}$ sealed vials. Mixing was with the aid of parylene-coated stirring bars. In vials sealed from air, $\left[\mathrm{O}_{2}\right]$ decreased linearly with time, indicating the kinetics of mitochondrial $\mathrm{O}_{2}$ consumption was zero-order. The rate of respiration $\left(k\right.$, in $\left.\mu \mathrm{M} \mathrm{O}_{2} \min ^{-1}\right)$ was thus the negative of the slope $\mathrm{d}\left[\mathrm{O}_{2}\right] / \mathrm{d} t$. $\mathrm{NaCN}$ inhibited respiration, confirming $\mathrm{O}_{2}$ was being consumed in the mitochondrial respiratory chain.
The calibration reaction contained PBS with $3 \mu \mathrm{M}$ Pd phosphor, $0.5 \%$ fat-free albumin, $50 \mu \mathrm{g} / \mathrm{mL}$ glucose oxidase and various concentrations of $\beta$-glucose. $\left[\mathrm{O}_{2}\right]$ was calculated using, $1 / \tau=1 / \tau^{o}+k_{q}\left[\mathrm{O}_{2}\right][11]$.

\section{Cellular ATP content}

Liver tissue fragments were homogenized in $0.5 \mathrm{~mL}$ of ice-cold $2 \%$ trichloroacetic acid for $2 \mathrm{~min}$. The supernatants were collected by centrifugation $(1000 \times g$ at $4^{\circ} \mathrm{C}$ for $5 \mathrm{~min}$ ) and stored at $-20^{\circ} \mathrm{C}$ until analysis. Immediately before ATP measurement, the samples were thawed and neutralized with $0.5 \mathrm{~mL} 100 \mathrm{mM}$ Trisacetate, $2 \mathrm{mM}$ EDTA (final $p \mathrm{H}, 7.75$ ). ATP concentration was determined using the Enliten ATP Assay System (Bioluminescence Detection Kit, Promega, Madison, WI). Briefly, $2.5 \mu \mathrm{L}$ of the supernatant was added to 25 $\mu \mathrm{L}$ of the luciferin/luciferase reagent. The luminescence intensity was then measured at $25^{\circ} \mathrm{C}$ using Glomax Luminometer (Promega, Madison, WI). The ATP standard curve ranged from $10 \mathrm{pM}$ to $100 \mathrm{nM}\left(R^{2}>0.9999\right)$.

\section{Urea synthesis}

Liver specimens were incubated at $37^{\circ} \mathrm{C}$ in $50 \mathrm{ml} \mathrm{KH}$ buffer continuously gassed with $95 \% \mathrm{O}_{2}: 5 \% \mathrm{CO}_{2}$. At indicated time points, specimens ( $\sim 80 \mathrm{mg}$ each) were taken from the incubation solution and placed in $1.0 \mathrm{~mL}$ $\mathrm{KH}$ buffer supplemented with $10 \mathrm{mM} \mathrm{NH} \mathrm{NH}_{4} \mathrm{Cl}$ and $2.5 \mathrm{mM}$ ornithine. The reactions were allowed to continue at $37^{\circ} \mathrm{C}$ for $50 \mathrm{~min}$ with continuous gassing as above. At the end of the incubation period, the specimens were discarded and the solution was analyzed for urea as described [12]. Blood urea nitrogen (BUN, $\mathrm{mmol} / \mathrm{L}$ ) was measured using standard laboratory methods with an LX20 multiple automated analyzer (Beckman Coulter, CA, USA). For conversion, BUN $(\mathrm{mg} / \mathrm{dL})=$ BUN $(\mathrm{mmol} / \mathrm{L}) \div 0.357$; Urea $(\mathrm{mg} / \mathrm{dL})=$ $\mathrm{BUN}(\mathrm{mg} / \mathrm{dL}) \times 2.14$.

A second protocol was employed, which involved incubating liver specimens (small fragments weighing about $300 \mathrm{mg}$ ) at $37^{\circ} \mathrm{C}$ in $50 \mathrm{ml} \mathrm{KH}$ buffer supplemented with $10 \mathrm{mM} \mathrm{NH}_{4} \mathrm{Cl}$ and $2.5 \mathrm{mM}$ ornithine and continuously gassed as above. At 0, 3 and $6 \mathrm{hr}$, an aliquot of the solution was taken for urea determination.

\section{Light microscopy}

Liver samples were fixed in $10 \%$ neutral formalin, dehydrated in increasing concentrations of ethanol, cleared with xylene and embedded in paraffin. Three micrometer sections were prepared from paraffin blocks and stained with haematoxylin and eosin.

\section{Electron microscopy}

Liver samples were immersed in McDowell and Trump fixative for $3 \mathrm{~h}$ at room temperature. Tissues were rinsed 


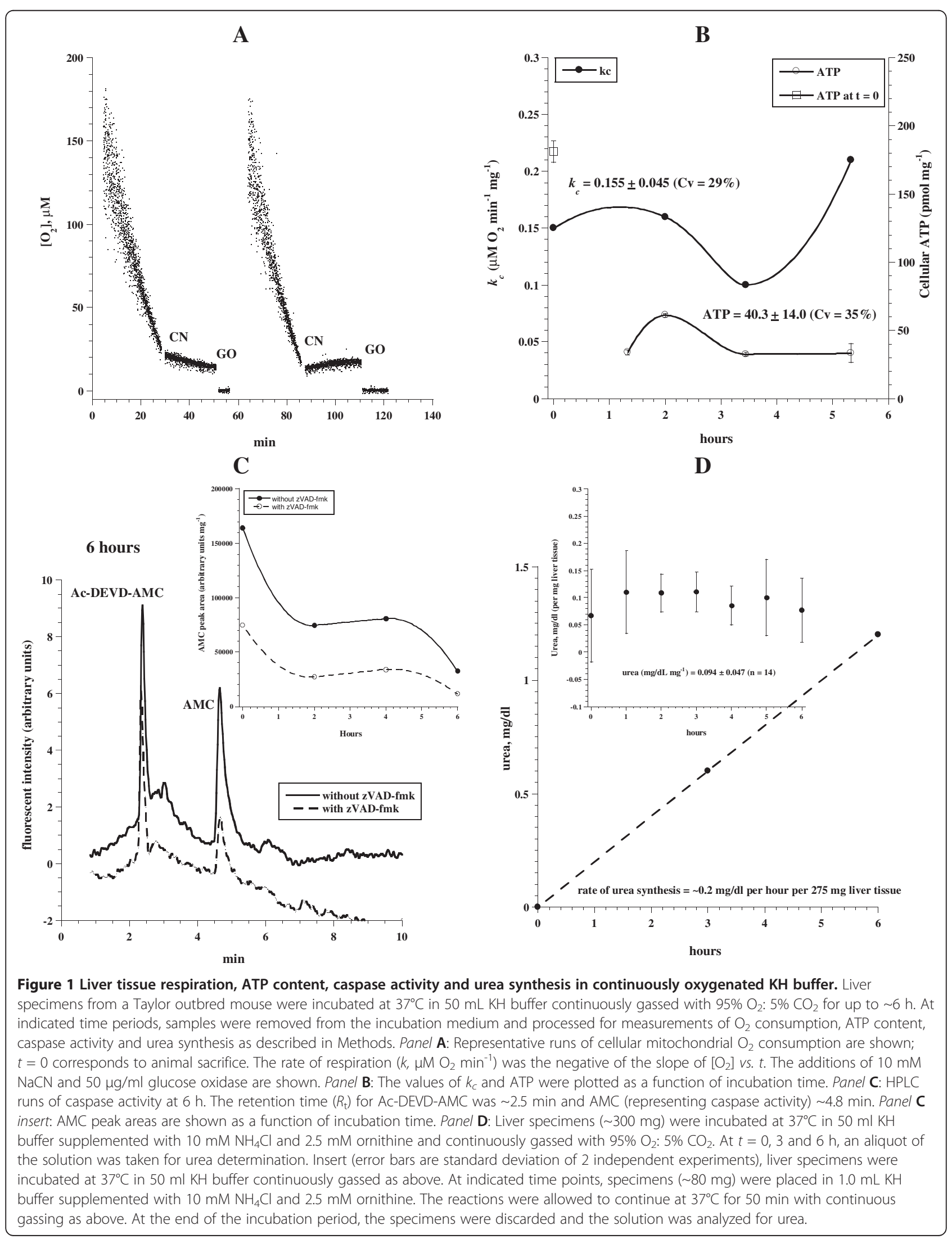


with phosphate buffer saline and fixed with $1 \%$ osmium tetroxide for $1 \mathrm{~h}$. Samples were washed with $\mathrm{dH}_{2} \mathrm{O}$, dehydrated in a series of graded ethanol and propylene oxide, infiltrated, embedded in Agar-100 epoxy resin and polymerized at $65^{\circ} \mathrm{C}$ for $24 \mathrm{~h}$. Blocks were trimmed and semi-thin and ultrathin sections were cut with Reichert Ultracuts, ultra-microtome. The semi-thin sections $(1 \mathrm{~mm}$ ) were stained with $1 \%$ aqueous toluidine blue on glass slides. The ultrathin sections $(95 \mathrm{~nm})$ on 200 mesh $\mathrm{Cu}$ grids were contrasted with uranyl acetate followed by lead citrate double stain. The grids were examined and photographed under a Philips CM10 transmission electron microscope.

Liver tissue preparation from Taylor outbred mice (specimens were incubated in KH buffer with continuous gassing with $95 \% \mathrm{O}_{2}: 5 \% \mathrm{CO}_{2}$ for up to $6 \mathrm{~h}$ ).

Liver fragments were collected as above and incubated at $37^{\circ} \mathrm{C}$ in $50 \mathrm{~mL} \mathrm{KH}$ buffer continuously gassed with $95 \%$ $\mathrm{O}_{2}: 5 \% \mathrm{CO}_{2}$ for up to $\sim 6 \mathrm{~h}$. At indicated time periods (Figure 1), samples were removed from the incubation medium and processed for measurements of cellular mitochondrial $\mathrm{O}_{2}$ consumption (expressed as, $k_{c}$ in $\mu \mathrm{M} \mathrm{O} \mathrm{O}_{2}$ $\mathrm{min}^{-1} \mathrm{mg}^{-1}$ ), ATP content ( $\mathrm{pmol} \mathrm{mg}{ }^{-1}$ ), caspase activity (arbitrary units $\mathrm{mg}^{-1}$ ) and urea synthesis $\left(\mathrm{mg} / \mathrm{dL} \mathrm{mg}^{-1}\right.$ ). Figure 1A shows representative runs of $\mathrm{O}_{2}$ consumption that were inhibited by cyanide $(\mathrm{CN})$, confirming the oxidation occurred in the mitochondrial respiratory chain.
The addition of glucose oxidase (GO) depleted the remaining $\mathrm{O}_{2}$ in the solution. The values (mean $\pm \mathrm{SD}$ ) of $k_{c}$ for $0 \leq t \leq 6 \mathrm{~h}$ were $0.155 \pm 0.045(\mathrm{n}=4$; coefficient of variation, $\mathrm{CV}=29 \%$ ), Figure $1 \mathrm{~B}$. The corresponding values of cellular ATP (Figure 1B, done in triplicates) for 1 $\leq t \leq 6 \mathrm{~h}$ were $40.3 \pm 14.0 \mathrm{pmol} \mathrm{mg}^{-1}(\mathrm{n}=4 ; \mathrm{CV}=35 \%$; please note the value of ATP at $t=0$ was $181.1 \pm 8.0$ ). These results show a reasonable in vitro stability of hepatocyte oxidative phosphorylation for about $6 \mathrm{~h}$. The sharp declined in cellular ATP in the first hour demonstrated an inability to fully sustain the in vivo status of hepatocyte bioenergetics.

Representative HPLC run for caspase activity is shown in Figure 1C. Figure $1 \mathrm{C}$ (insert) shows a relatively low AMC peak area (reflecting caspase activity) at $6 \mathrm{~h}$. AMC peak areas in the presence of the pancaspase inhibitor zVAD-fmk were reduced by 55 to $65 \%$ (Figure 1C), confirming the cleavage reaction was mainly due to caspase activity.

Urea synthesis by liver specimens is shown in Figure 1D. A steady increase in the rate of urea synthesis was demonstrated up to $6 \mathrm{~h}$. Briefly, liver specimens ( 300 mg) were incubated at $37^{\circ} \mathrm{C}$ in $50 \mathrm{ml} \mathrm{KH}$ buffer supplemented with $10 \mathrm{mM} \mathrm{NH}_{4} \mathrm{Cl}$ and $2.5 \mathrm{mM}$ ornithine and continuously gassed with $95 \% \mathrm{O}_{2}: 5 \% \mathrm{CO}_{2}$. At $t=0,3$ and $6 \mathrm{~h}$, an aliquot of the solution was taken for urea determination. The rate of urea synthesis was $\sim 0.2 \mathrm{mg} / \mathrm{dL}$ per h per $275 \mathrm{mg}$.

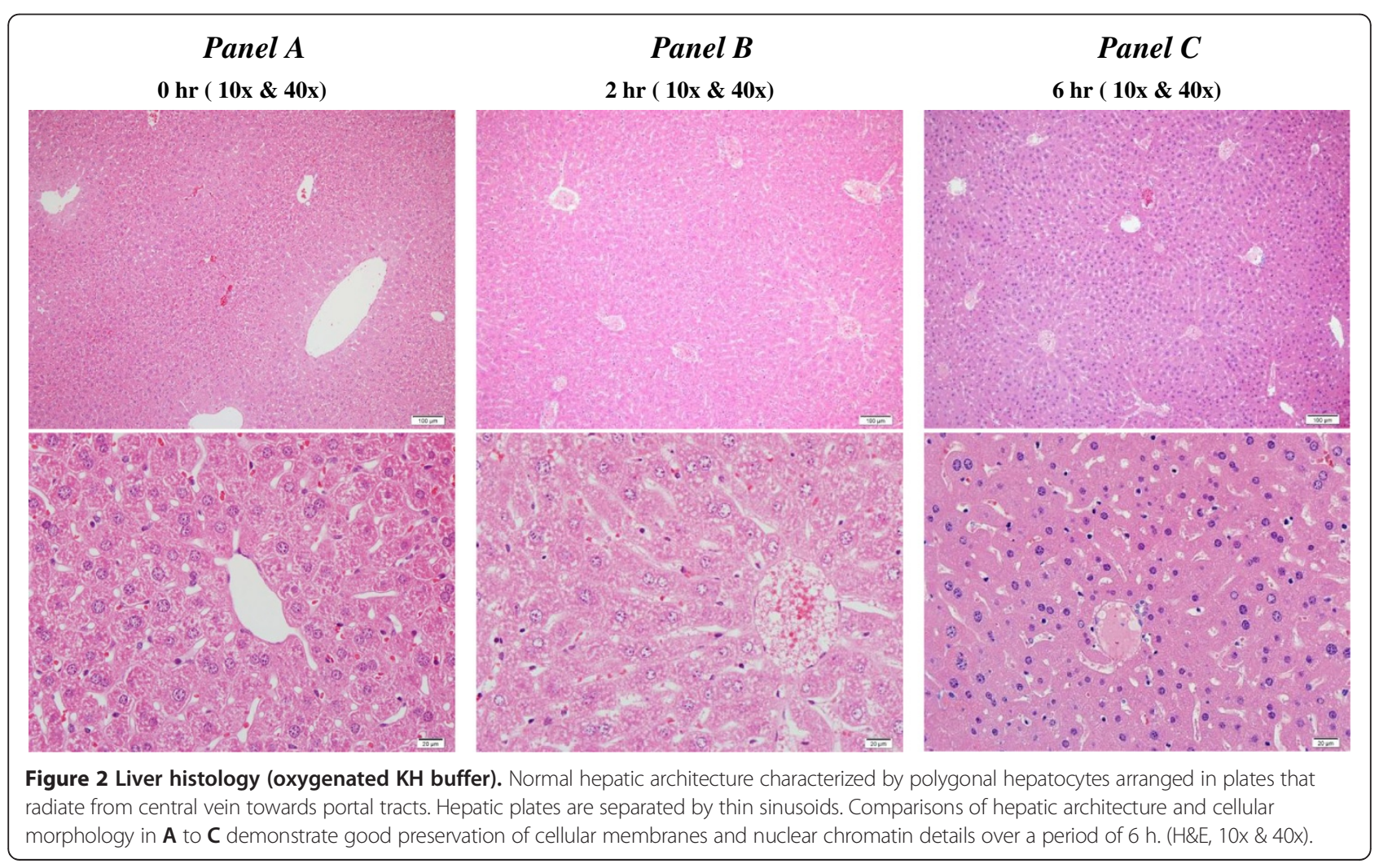


In Figure 1D (insert), liver specimens were incubated at $37^{\circ} \mathrm{C}$ in $50 \mathrm{ml} \mathrm{KH}$ buffer continuously gassed as above. At indicated time points, specimens $(\sim 80 \mathrm{mg})$ were placed in $1.0 \mathrm{~mL} \mathrm{KH}$ buffer supplemented with $10 \mathrm{mM} \mathrm{NH}_{4} \mathrm{Cl}$ and $2.5 \mathrm{mM}$ ornithine. The reactions were allowed to continue at $37^{\circ} \mathrm{C}$ for 50 min with continuous gassing as above. At the end of the incubation period, the specimens were discarded and the solution was analyzed for urea. The concentrations of urea (over $50 \mathrm{~min} ; 2$ independent experiments) were $0.134 \pm$ $0.017 \mathrm{mg} / \mathrm{dL} \mathrm{mg}^{-1}(0<t \leq 6 \mathrm{~h}, \mathrm{n}=14, \mathrm{CV}=13 \%)$. Thus, urea synthesis by the preparations was stable for up $6 \mathrm{~h}$. Similar results were obtained for the C57 strain of mice.

Figure 2 shows normal polygonal hepatocytes arranged in plates that radiate from central vein towards portal tracts. The hepatic plates were separated by thin sinusoids. Comparisons of the architecture between $t=$
$0, \mathrm{t}=2 \mathrm{~h}$ and $t=6 \mathrm{~h}$ demonstrate a good preservation of the hepatic structure over $6 \mathrm{~h}$.

The electron microscopy images also confirmed preserved hepatocyte microarchitecture, but with mild swelling of the mitochondria at $6 \mathrm{~h}$ in both TO and $\mathrm{C} 57 \mathrm{Bl} / 6$ mouse strains (Figure 3).

Liver tissue preparation from $\mathrm{C} 57 \mathrm{Bl} / 6$ mice (specimens were incubated in KH buffer without continuous oxygenation for up to $6 \mathrm{~h}$ ).

The need for continuous gassing with $\mathrm{O}_{2}: \mathrm{CO}_{2}$ was investigated in $\mathrm{C} 57 \mathrm{Bl} / 6$ mice. Liver fragments were incubated at $37^{\circ} \mathrm{C}$ in $50 \mathrm{~mL} \mathrm{KH}$ buffer without continuous gassing with $95 \% \mathrm{O}_{2}: 5 \% \mathrm{CO}_{2}$. At indicated time periods (Figure 4), samples were removed from the incubation medium and processed for the measurements described for Figure 1. Figure 4A-B shows representative runs of $\mathrm{O}_{2}$ consumption. The rate of respiration

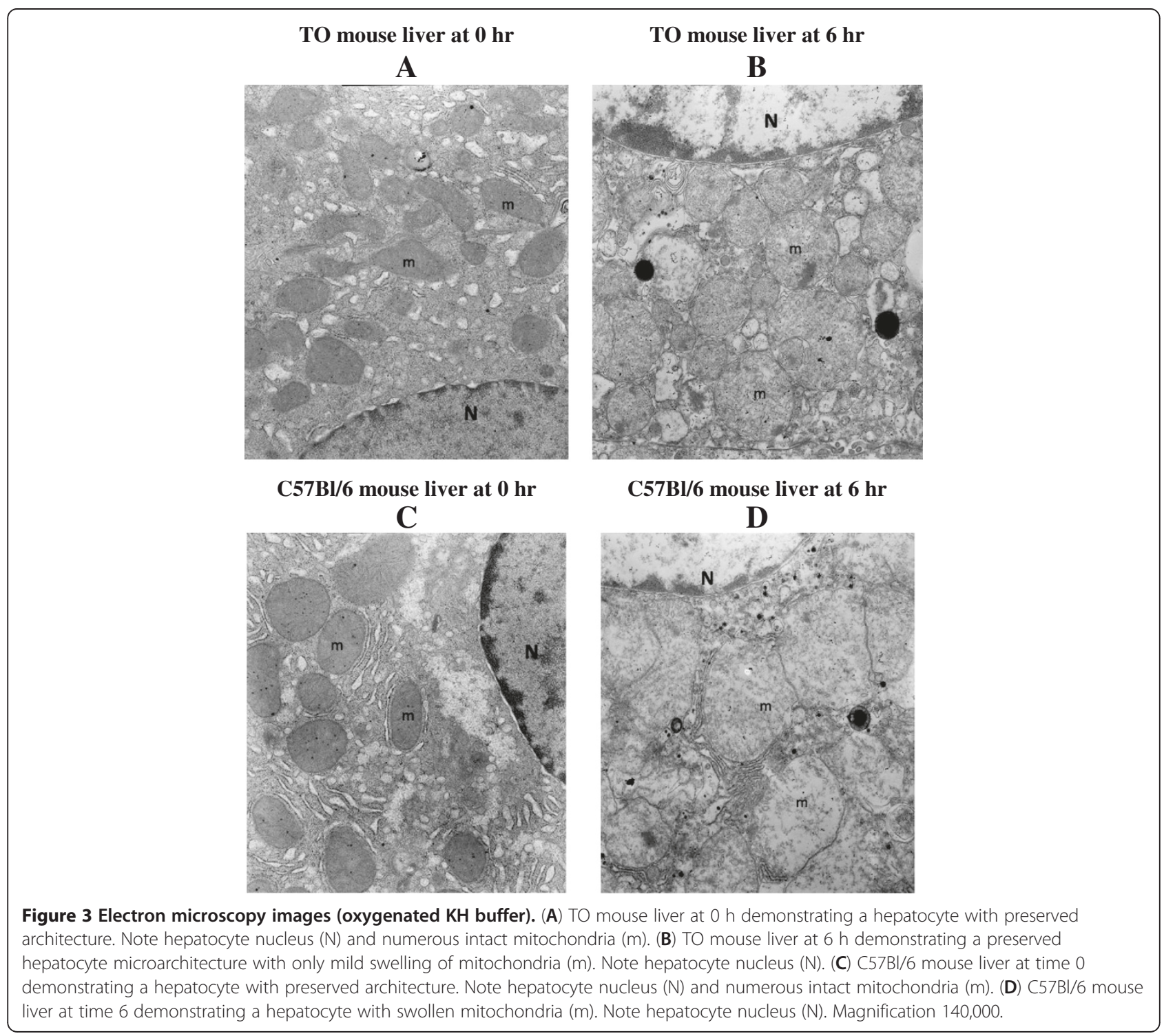




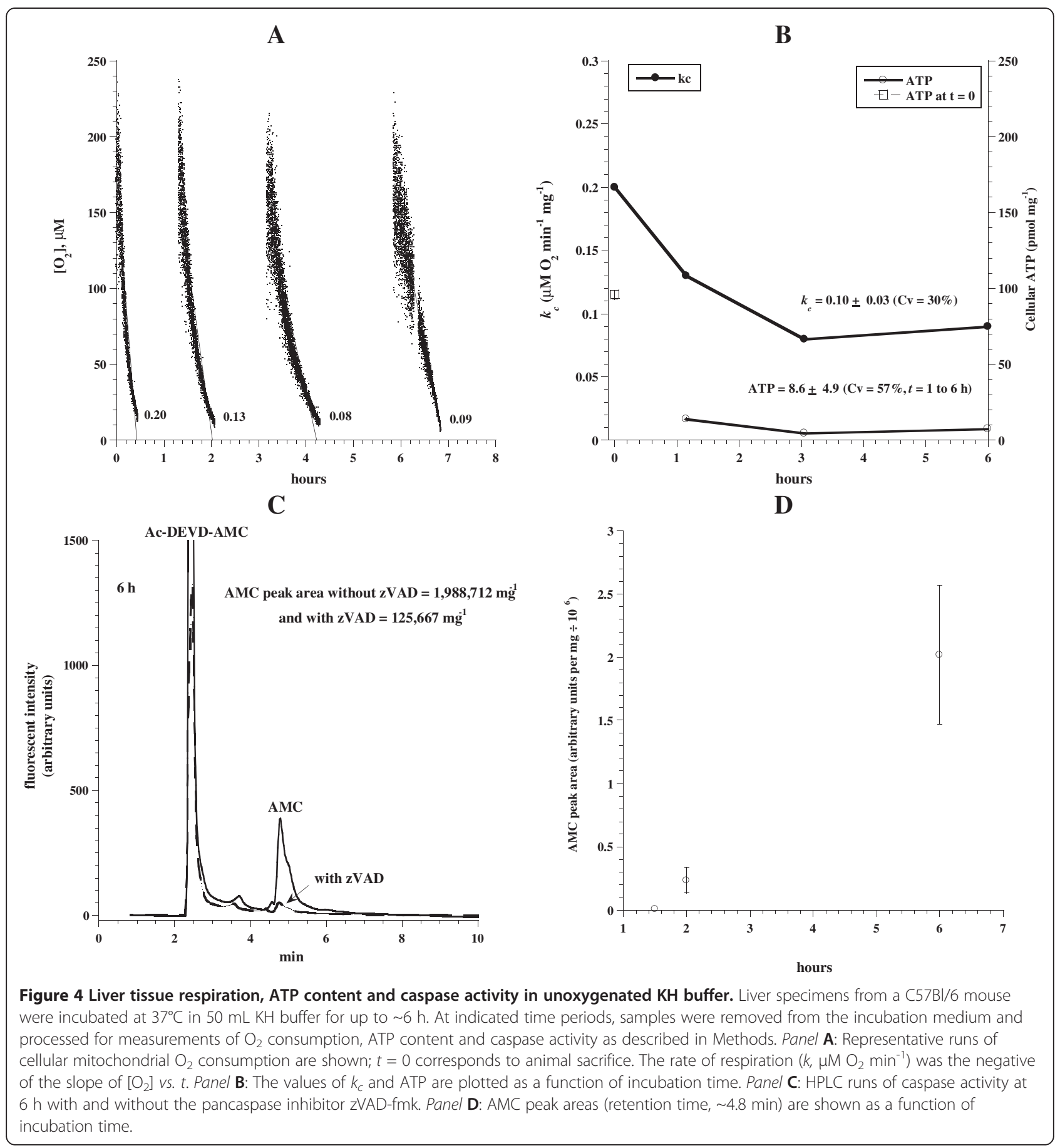

progressively decreased with time $\left(k_{c}=0.2 \mu \mathrm{M} \mathrm{O} \min ^{-1}\right.$ $\mathrm{mg}^{-1}$ at $t=0 \mathrm{~h}$ and 0.09 at $t=6 \mathrm{~h}$ ). This more than $50 \%$ reduction in the respiration was also accompanied by relatively low cellular ATP content. For $1<t \leq 6 \mathrm{~h}$, cellular ATP was $8.8 \pm 4.9 \mathrm{pmol} \mathrm{mg}^{-1}$ (Figure 4B), which was $21 \%$ of that shown with continuous oxygenation (Figure 1B). Consistently, intracellular caspase activity markedly increased at hour 6 (Figure 4C-D). The AMC peak area at $6 \mathrm{~h}$ without zVAD-fmk was 1,988,712 and with
zVAD-fmk was 125,667 (Figure 4C). The corresponding values with continuous oxygenation were 32,477 and 11,372 , respectively (see Figure $1 \mathrm{C}$ ). Thus, caspase activity increased about 6-fold without oxygenation. These results showed the link between hepatocyte bioenergetics and induction of caspases; that is, increased caspase activity was associated with impaired cellular bioenergetics. EM images of the liver at $t=0$ demonstrated hepatocytes with preserved architecture, nucleus, mitochondria, rough 
endoplasmic reticulum, microvilli and cytoplasmic lipid vacuoles (Figure 5A). Numerous cytoplasmic vesicles, however, were present at $t=6 \mathrm{~h}$, representing swollen disintegrating mitochondria under the experimental conditions (Figure 5B).

\section{Significance}

The main purpose of this work was to develop in vitro method suitable for studying the effects of toxins and drugs on hepatocyte metabolic biomarkers (cellular respiration, ATP content, caspase activity and urea synthesis). The preparation described in Figure 1 resulted in reasonable preservation of liver bioenergetics with minimum caspase activity for up to $6 \mathrm{~h}$. The response of this in vitro system is demonstrated by induction of intracellular caspases by the hepatotoxin dactinomycin (Additional file 1: Figure S1, Supplementary Materials).

The success of this procedure relies on three important steps. The first step involves rapid (within $30 \mathrm{sec}$ ) excision of thin liver fragments while the organ is still perfused. The second step involves immediate immersion of the excised tissue in ice-cold $\mathrm{KH}$ buffer (continuously gassed with 95\% $\mathrm{O}_{2}: 5 \%$ $\mathrm{CO}_{2}$ ). If needed, specimens were cut into smaller slices using a 4-mm punch biopsy device while in the oxygenated icecold buffer. The third step involves incubating the fragments in a large volume (e.g., $50 \mathrm{~mL}$ ) of $\mathrm{KH}$ buffer with continuous gassing with $95 \% \mathrm{O}_{2}: 5 \% \mathrm{CO}_{2}$. Having adhered to these steps, the coefficient of variation for the rate of respiration was $13 \%(0 \leq t \leq 6 \mathrm{~h})$, ATP content $53 \%(1 \leq t \leq 6 \mathrm{~h})$, and urea synthesis $13 \%(0 \leq t \leq 6 \mathrm{~h})$.
Cellular ATP content was significantly higher at $t=0$ (Figure 1B, open square), reflecting the inability to maintain the in vivo level of hepatocyte ATP. Despite this limitation, the remaining parameters (hepatocyte respiration, urea synthesis, caspase activity, histology and organelles) were relatively preserved over $6 \mathrm{~h}$ (Figures 1, 2, 3).

As noted in Figures 4, 5, cellular ATP was depleted and cellular respiration was markedly decreased in unoxygenated buffer. These changes were accompanied by a "storm" of intracellular caspase activity, which is known to disturb mitochondrial functions ("the mitochondrial cell death pathway").

The findings here highlight the sensitivity of hepatocytes to hypoxia and poor tissue perfusion. As shown (Figures 4, 5), the relative tissue hypoxia induced a collapse in hepatocyte bioenergetics (impaired respiration and ATP production) and caspase induction, which further impede cellular function and repair.

Active caspases permeabilize the inner mitochondrial membranes, resulting in a collapse in the proton motive force, loss of electrochemical potential and uncoupling of oxidative phosphorylation [5]. This process leads to rapid depletion of cellular nutrients, metabolic fuels and ATP. These consequences contribute to further hepatocyte damages. Thus, the initial cellular insults become compounded by subsequent mitochondrial derangements.

Another limitation of this preparation is the relative short $(6 \mathrm{~h})$ in vitro incubation. Longer experiments produced air bubbles in the hepatocytes and bacterial overgrowth. Future studies are needed to overcome these technical limitations.
A

TO mouse liver at $0 \mathrm{~h}$

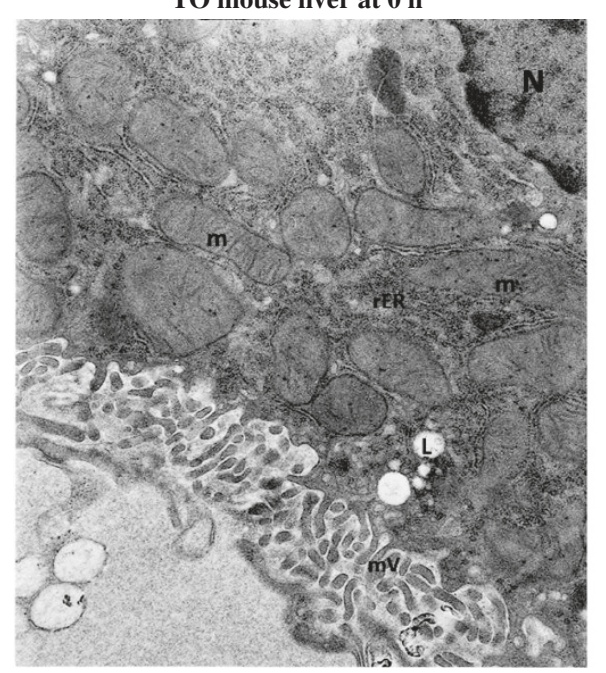

B

TO mouse liver at $6 \mathrm{~h}$

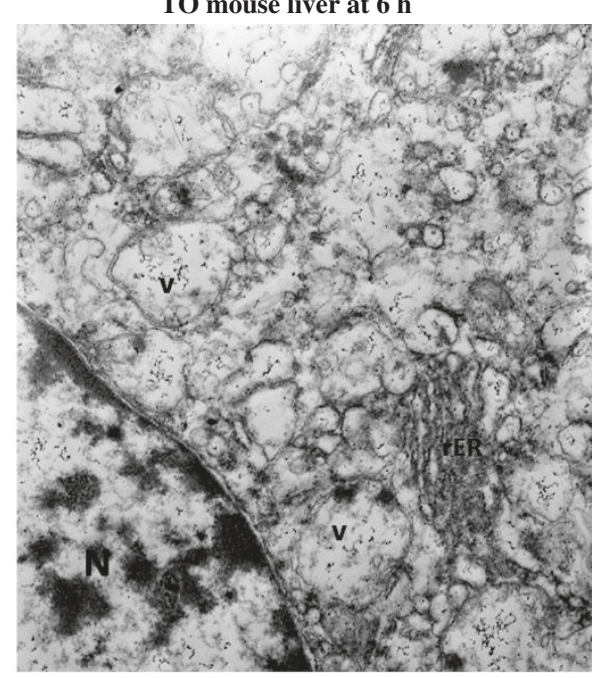

Figure 5 Electron microscopy images (unoxygenated KH buffer). (A) Liver at time 0 demonstrating hepatocytes with preserved architecture. Note hepatocyte nucleus $(\mathrm{N})$, numerous intact mitochondria $(\mathrm{m})$, rough endoplasmic reticulum (rER), microvilli $(\mathrm{mV})$ and cytoplasmic lipid vacuoles (L). (B) Liver at $6 \mathrm{~h}$ demonstrating hepatocytes with numerous cytoplasmic vesicles (v), rough endoplasmic reticulum (rER) and a nucleus (N). Some of the vesicles probably represent swollen disintegrating mitochondria under experimental conditions. Magnification 140,000. 
In summary, the described method is relatively simple and requires minimal tissue handling. It permits comprehensive in vitro analyses for up to $6 \mathrm{~h}$. Its main advantage is using one animal for multiple biomarkers. Other advantages include evading extensive tissue manipulation and collagenase digestion required for single cell preparations.

\section{Additional file}

Additional file 1: Figure S1. HPLC runs of liver tissue caspase activity with and without $8 \mu \mathrm{M}$ dactinomycin. Two independent experiments are shown. Liver fragments (40 mg each) from C57Bl/6 mice were incubated in $0.5 \mathrm{~mL}$ oxygenated $\mathrm{KH}$ buffer supplemented with $74 \mu \mathrm{M}$ DEVD-AMC with (dashed lines) and without (solid lines) $42.8 \mu \mathrm{M}$ zVAD-fmk. The incubations were allowed to continue at $37^{\circ} \mathrm{C}$ with and without $8 \mu \mathrm{M}$ dactinomycin for $60 \mathrm{~min}$. The tissues were then disrupted by vigorous homogenization for $2 \mathrm{~min}$, sonication for $3 \mathrm{~min}$ and 10 passages through a $27-G$ needle. The supernatants were collected by centrifugation ( 16,300 $\mathrm{g}$ for $90 \mathrm{~min}$ ) through Microcentrifuge Filter (nominal molecular weight limit $=10,000$ Dalton, $_{\text {Sigma }}{ }^{\circ}$ ), separated on HPLC, and analyzed for the free fluorogenic AMC moiety. The analysis was performed on a Waters reversed-phase HPLC system. The column, $4.6 \times 250 \mathrm{~mm}$ Beckman Ultrasphere IP column, was operated at $25^{\circ} \mathrm{C}$ at $1.0 \mathrm{ml} / \mathrm{min}$. For AMC detection, the excitation wavelength was $380 \mathrm{~nm}$ and the emission wavelength $460 \mathrm{~nm}$. The running solvents (isocratic) were HPLC-grade $\mathrm{CH}_{3} \mathrm{CN}: \mathrm{H}_{2} \mathrm{O}[1: 3, \mathrm{v} / \mathrm{v}]$ (Solvent $\mathrm{A}$ ) and $\mathrm{dH}_{2} \mathrm{O}$ (Solvent B). The $R_{\mathrm{t}}$ for AcDEVD-AMC was $\sim 4.5 \mathrm{~min}$ and $\mathrm{AMC} \sim 18.5 \mathrm{~min}$. The AMC peak areas with and without zVAD are shown.

\section{Abbreviation}

KH: Krebs-Henseleit; Ac-DEVD-AMC: the caspase-3 substrate $\mathrm{N}$-acetyl-asp-gluval-asp-7-amino-4-methylcoumarin; CV: Coefficient of variation; $\mathrm{Pd}$ phosphor: $\mathrm{Pd}(\mathrm{II})$ complex of meso-tetra-(4-sulfonatophenyl)tetrabenzoporphyrin; zVAD-fmk: Caspase inhibitor I [N-benzyloxycarbonyl-valala-asp(O-methyl)-fluoromethylketone]; NaCN: Sodium cyanide; TO: Taylor

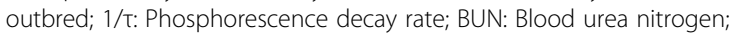
$\mathrm{H} \& \mathrm{E}$ : Haematoxylin and eosin; $k$ : Rate of cellular respiration (in $\mu \mathrm{M} \mathrm{O}_{2} \mathrm{~min}^{-1}$ ); $k_{c}$ : Corrected rate of cellular respiration (in $\mu \mathrm{M} \mathrm{O}_{2} \mathrm{~min}^{-1} \mathrm{mg}^{-1}$ ); $\mathrm{GO}$ : Glucose oxidase.

\section{Competing interests}

The authors declare that they have no competing interests.

\section{Authors' contributions}

ASA and BA designed the study, carried out the analysis, interpreted the data and drafted the manuscript. SA and AA performed the histology. AKS supervised the progress and critically revised the manuscript. All authors read and approved the final manuscript.

\section{Acknowledgements}

This work was supported by a grant from the UAE University.

\section{Author details}

'Departments of Medicine, United Arab Emirates University, P.O. Box 15551, Al Ain, UAE. ²Departments of Pathology, United Arab Emirates University, P.O. Box 15551, Al Ain, UAE. ${ }^{3}$ Departments of Pediatrics, United Arab Emirates University, P.O. Box 15551, Al Ain, UAE.

Received: 2 December 2012 Accepted: 23 February 2013 Published: 25 February 2013

\section{References}

1. Al Samri MT, Al Shamsi M, Al-Salam S, Marzouqi F, Al Mansouri A, et al: Measurement of oxygen consumption by murine tissues in vitro. J Pharmacol Toxicol Meth 2011, 63:196-204.
2. Al-Shamsi M, Al-Samri M, Al-Salam S, Conca W, Benedict S, et al: Biocompatibility study of mesoporous silicate particles with cellular bioenergetics in murine tissues. Chem Res Toxicol 2010, 11:1796-1805.

3. Al-Salam S, Balhaj G, Al-Hammadi S, Sudhadevi M, Tariq S, et al: In Vitro study of calcined mesoporous silica nanoparticles in mouse lung. Toxicology Sciences 2011, 122:86-99.

4. Tao Z, Jones E, Goodisman J, Souid A-K: Quantitative measure of cytotoxicity of anticancer drugs and other agents. Anal Biochem 2008, 381:43-52.

5. Green DR, Kroemer G: The pathophysiology of mitochondrial cell death. Science 2004, 305:626-629.

6. Ricci JE, Muñoz-Pinedo C, Fitzgerald P, Bailly-Maitre B, Perkins GA, et al: Disruption of mitochondrial function during apoptosis is mediated by caspase cleavage of the p75 subunit of complex I of the electron transport chain. Cell 2004, 117:773-786.

7. Hao Z, Duncan GS, Chang C-C, Elia A, Fang M, Wakeham A, Okada H, Calzascia T, Jang YJ, You-Ten A, Yeh WC, Ohashi P, Wang X, Mak TW: Specific ablation of the apoptotic functions of cytochrome $c$ reveals a differential requirement of cytochrome $c$ and Apaf-1 in apoptosis. Cell 2005, 121:579-591.

8. Tao Z, Penefsky HS, Goodisman J, Souid A-K: Caspase activation by cytotoxic drugs (the caspase storm). Mol Pharm 2007, 4:583-595.

9. Dang CV: Links between metabolism and cancer. Genes Dev 2012, 26:877-890.

10. Shaban S, Marzouqi F, Al Mansouri A, Penefsky H, Souid AK: Oxygen measurements via phosphorescence. Comp Meth Programs Biomed 2010, 100:265-268.

11. Lo LW, Koch CJ, Wilson DF: Calibration of oxygen-dependent quenching of the phosphorescence of Pd-meso-tetra (4-carboxyphenyl) porphine: A phosphor with general application for measuring oxygen concentration in biological systems. Anal Biochem 1996, 236:153-160.

12. Takeyori S, Nobuhiko K: Analysis of regulatory factors for urea synthesis by isolated perfused rat liver. J Biochem 1975, 77:659-669.

\section{doi:10.1186/1756-0500-6-70}

Cite this article as: Alfazari et al: A preparation of murine liver fragments for in vitro studies: liver preparation for toxicological studies. BMC Research Notes 2013 6:70.

\section{Submit your next manuscript to BioMed Central and take full advantage of:}

- Convenient online submission

- Thorough peer review

- No space constraints or color figure charges

- Immediate publication on acceptance

- Inclusion in PubMed, CAS, Scopus and Google Scholar

- Research which is freely available for redistribution 